\title{
ARECACEAE: UMA ESTRATÉGIA DIFERENCIADA PARA O ENSINO DE BOTÂNICA EM UMA ESCOLA DE ENSINO MÉDIO NA ILHA DE COTIJUBA, PARÁ, BRASIL
}

Jone Clebson Ribeiro Mendes ${ }^{1}$, Adrhyann Jullyanne de Sousa Portilho ${ }^{2}$, Ana Cristina Andrade de Aguiar-Dias ${ }^{3}$, Kelly Liane da Silva Sampaio ${ }^{4}$ \& Luciana de Nazaré Farias $^{5}$

${ }^{1}$ Doutorando do Curso de Pós-Graduação em Botânica pela Universidade Federal Rural de Pernambuco - UFRPE, Recife, PE, Brasil. E-mail: jonecmendes5@gmail.com

${ }^{2}$ Doutoranda do Curso de Pós-Graduação em Ciências Médicas pela Universidade Federal do Ceará -UFC, Fortaleza - CE, Brasil.

${ }^{3}$ Doutora em Biologia Vegetal, Professora Adjunto IV da Universidade Federal do Pará - UFPA, Belém, PA, Brasil.

${ }^{4}$ Mestre em Biodiversidade e Evolução pelo Museu Paraense Emílio Goeldi - MPEG, Belém, PA, Brasil.

${ }^{5}$ Doutora em Educação em Ciências e Matemáticas, Professora Assistente II da Universidade do Estado do Pará - UEPA, Belém, PA, Brasil.

\section{Recebido em: 06/04/2019 - Aprovado em: 10/06/2019 - Publicado em: 30/06/2019 DOI: 10.18677/EnciBio_2019A170}

\begin{abstract}
RESUMO
A importância das espécies de palmeiras (Arecaceae) é expressiva devido à grande diversidade de produtos que delas podem ser obtidos (p. ex. alimentação, construções, artesanato, paisagismo e medicina alternativa. Assim, como sua importância social, cultural ou religiosa para comunidades tradicionais e indígenas. Objetivou-se avaliar na comunidade escolar da Escola Estadual de Ensino Fundamental e Médio Professora Marta da Conceição (E.E.E.F.M.P.M.C.) o conhecimento social, cultural e econômico sobre as palmeiras, e como estas plantas podem serem indicadoras nas aulas teóricas e de campo no ensino de Ciências e Biologia. Para isso, foram realizadas visitas, entrevistas gravadas (18) e aplicações de questionários (100), no período de agosto à novembro de 2018, com método de amostragem acidental. Os informantes listaram 27 espécies de palmeiras, que apresentam expressiva importância cultural e econômica na comunidade, sendo utilizadas para diferentes finalidades, dentre estas, se destaca o uso alimentício (12 spp.), artesanal (9 spp.), construção/doméstica (4 spp.), cosmético (3 spp.) e medicinal (8 spp.) e assim como alguns relatos pelos moradores, sobre algumas espécies. Com isso, foi apresentada estratégias de ensino e assim, houve a positivação pelos professores de Ciências e Biologia na inserção das palmeira no ensino-aprendizagem, os quais podem conciliar o conhecimento popular dos alunos adquiridos através da convivência familiar ao conhecimento escolar, valorizando a cultura dos educandos e possibilitando, que eles adquiram informações a respeito das palmeiras como os mais variados usos, nome científico, morfologia e ecologia.
\end{abstract}

PALAVRAS-CHAVE: Amazônia; Aprendizagem-significativa; Ensino-botânica. 


\title{
ARECACEAE: A DIFFERENTIATED STRATEGY FOR BOTANICAL EDUCATION IN A MIDDLE SCHOOL IN COTIJUBA ISLAND, PARÁ, BRAZIL
}

\begin{abstract}
The importance of palm species (Arecaceae) is significant due to the great diversity of products that can be obtained from them (eg. food, buildings, handicrafts, landscaping and alternative medicine). Thus, as its social, cultural or religious importance for traditional and indigenous communities. The objective was to evaluate in the school community of State School of Elementary and Middle School Teacher Marta da Conceição (E.E.E.F.M.P.M.C) the social, cultural and economic knowledge about the palms, and how these plants can be indicative in the theoretical and field classes in the teaching of Sciences and Biology. For that, visits, recorded interviews (18) and applications of questionnaires (100) were carried out from august to november 2018, using an accidental sampling method. The informants listed 27 species of palm trees, which have significant cultural and economic importance in the community, being used for different purposes, among them, the use of food (12 spp.), artisanal (9 spp. spp.), cosmetic (3 spp.) and medicinal (8 spp.) and as well as some reports by the residents about some species. With this, teaching strategies were presented and, thus, there was the positivation by the teachers of Science and Biology in the insertion of palm trees in teaching-learning, which can reconcile the popular knowledge of the students acquired through the familiar coexistence to the school knowledge, valuing the culture of the students and enabling them to acquire information about palm trees as the most varied uses, scientific name, morphology and ecology.
\end{abstract}

KEYWORDS: Amazon; Learning-meaningful; Teaching-botany.

\section{INTRODUÇÃO}

A família Arecaceae Schultz Sch. é constituída por um grupo de espécies genericamente conhecidas como palmeiras, que abrange cerca de 2.700 espécies e 250 gêneros com distribuição principalmente tropical e subtropical (DRANSFIELD et al., 2008). No Brasil, está representada por 37 gêneros e 300 espécies, distribuídas em todas as regiões, com maior diversidade na Floresta Amazônica (149 spp.) e no Cerrado (98 spp.) (BFG 2018). As espécies dessa família são consideradas as aristocratas do reino vegetal, sendo denominadas pelos botânicos de "príncipes das florestas", devido seu porte altaneiro e elegante que as distingue facilmente de outras plantas (BONDAR, 1964; LORENZI, 1996).

Arecaceae, juntamente com as famílias Poaceae Barnhart e Fabaceae Lindl., destaca-se em função de sua utilização no passado e atualmente pela humanidade (HENDERSON et al., 1995; MAUNDER et al., 2001), desde tempos remotos, as grandes civilizações orientais como as do mediterrâneo contavam com as palmeiras como elementos característicos de sua paisagem e habitat (SODRÉ, 2005). Este mesmo autor afirma que os povos da antiguidade encontravam também nestas plantas suas qualidades nutritivas, servindo de base de alimentação para os habitantes do norte da África e sudoeste da Ásia, enquanto que, ainda eram utilizadas como matéria prima para construções.

Particularmente para a região tropical, a importância das palmeiras é ainda mais expressiva devido à grande diversidade de produtos que delas podem ser obtidos (p. ex. alimentação, construções, artesanato, paisagismo e medicina alternativa) e tem sido demonstrada em inúmeros estudos (CAMPOS; EHRINGHAUS, 2003; ROCHA; SILVA, 2005; ALBÁN et al., 2008; NASCIMENTO 
2010). As palmeiras são provavelmente a família de plantas mais comumente usadas por ameríndios e populações rurais na Amazônia (BATES, 1988; BORCHSENIUS et al., 1998; SANTOS; COELHO-FERREIRA, 2012) e, portanto, têm um papel chave na subsistência de muitos comunidades (ANDERSON, 1991; BYG; BALSLEV, 2006; SANTOS; COELHO-FERREIRA, 2011).

Desse modo, a investigação da percepção local sobre a importância das palmeiras é de grande interesse, pois, além de integrar o sistema de valores de uma cultura, tal saber é importante para o êxito de práticas voltadas para a conservação florestal, com a geração de renda para as comunidades extrativistas (BYG; BALSLEV, 2001). Ausubel (1982) levanta em seus estudos a importância do conhecimento prévio que o aluno apresenta, ressaltando a importância de sua valorização para que se consiga sucesso na aprendizagem, sendo esta de fato significativa. Neste aspecto, Berkes et al. (1998) argumentaram que o conhecimento local, cultural e econômico pode complementar o conhecimento científico, fornecendo experiências e práticas através da vivência na sua localidade e respondendo adaptativamente a mudanças nestes ecossistemas.

Dessa forma, é importante identificar as principais características de cada cadeia, por meio de informações referentes ao número aproximado de pessoas ou famílias envolvidas nas diferentes etapas de produção, que espécies vegetais utilizam, a época e locais de coleta, armazenamento, beneficiamento e comercialização (MACHADO, 2008), conhecimento este, que deve ser ampliado dentro de sala aula, como recurso no processo educacional, dando valores ao ensino de Botânica, tanto social, como econômico e cultural.

Freire e Shor (2008) mostram que as novas metodologias da educação a partir do século XX, devem ser problematizadora, isto é, fazer dos temas escolhidos para os estudos, uma relação entre o que é aprendido em sala de aula, aproximando com à vivência cotidiana do indivíduo, através da valorização dos saberes, estabelecendo vínculos diretos entre o conhecimento disciplinar e sua realidade. Freire (1987, p. 128) ainda aponta que:

O estudante constrói o seu próprio conhecimento, sendo que cada estudante o faz de modo idiossincrático, pois o processo depende fundamentalmente do que o estudante já possui como bagagem teórica, de seu conhecimento anterior, sobre 0 qual ele construirá 0 novo conhecimento, de forma que o resultado final do processo de aprendizagem é também diferente para cada estudante.

Em consonância com essas ideias, repensou e planejou-se estratégias metodológicas inovadoras, visando à superação do método de memorização, por práticas pedagógicas motivadoras, onde foi criado o Projeto "Arecaceae do dia a dia", com intuito de dinamizar o ensino através de novas práticas metodológicas, conforme a Base Nacional Comum Curricular - BNCC (BRASIL, 2018), promovendo um diálogo de saberes entre a comunidade escolar, e como estas poderiam contribuir em mudanças no conhecimento, especificamente no processo ensinoaprendizagem no conteúdo de Botânica, mediante estratégias de atividades práticas capazes de tornar o aprendizado dinâmico e prazeroso, despertando nestes agentes envolvidos com a educação, a importância dos conhecimentos e utilização das plantas no seu dia a dia.

É imprescindível destacar que as competências gerais da BNCC, cumpre uma importante ação do $\S 1^{\circ}$ do Artigo $1^{\circ}$ da Lei de Diretrizes e Bases da Educação Nacional (LDB, Lei oㅜ 9.394/1996), tais como: 
I - valorizar e utilizar os conhecimentos historicamente construídos sobre o mundo físico, social, cultural e digital para entender e explicar a realidade, continuar aprendendo e colaborar para a construção de uma sociedade justa, democrática e inclusiva; II - valorizar e fruir as diversas manifestações artísticas e culturais, das locais às mundiais, e também participar de práticas diversificadas da produção artístico-cultural; e III - valorizar a diversidade de saberes e vivências culturais e apropriar-se de conhecimentos e experiências que the possibilitem entender as relações próprias do mundo do trabalho e fazer escolhas alinhadas ao exercício da cidadania e ao seu projeto de vida, com liberdade, autonomia, consciência crítica e responsabilidade (BRASIL, 2018, p.9).

Assim, este estudo objetivou-se avaliar na comunidade escolar da Escola Estadual de Ensino Fundamental e Médio Professora Marta da Conceição (E.E.E.F.M.P.M.C.), o conhecimento social, cultural e econômico sobre as palmeiras, e como estas plantas podem serem indicadoras nas aulas teóricas e de campo no ensino de Ciências e Biologia, proporcionando a troca de saberes entre o popular e o científico e assim, minimizando os efeitos do distanciamento das pessoas em relação às plantas, e inserindo-as no processo de ensino-aprendizagem dessa região.

\section{Área de estudo}

\section{MATERIAL E MÉTODOS}

Este estudo foi realizado na llha de Cotijuba (1'13'00”S 48³1'59”W) (Fig. 1) pertencentes a área insular do município de Belém, Pará, Brasil. Limita-se ao norte pela baía de Marajó; ao Sul pelo furo do Mamão, que a separa das ilhas de Jutuba e Paquetá; à Leste pela ilha de Tatuóca e à Oeste pelo canal de Cotijuba, posicionado nas imediações a extremo oeste da llha e servindo de ligação entre a baía do Guajará e o rio Pará (SÁNCHEZ, 2005). Sua área possui cerca de $60 \mathrm{~km}^{2}$ e uma costa com $15 \mathrm{~km}$ de praias praticamente inexploradas, apresentando uma população de aproximadamente 6.000 habitantes (IBGE, 2018).

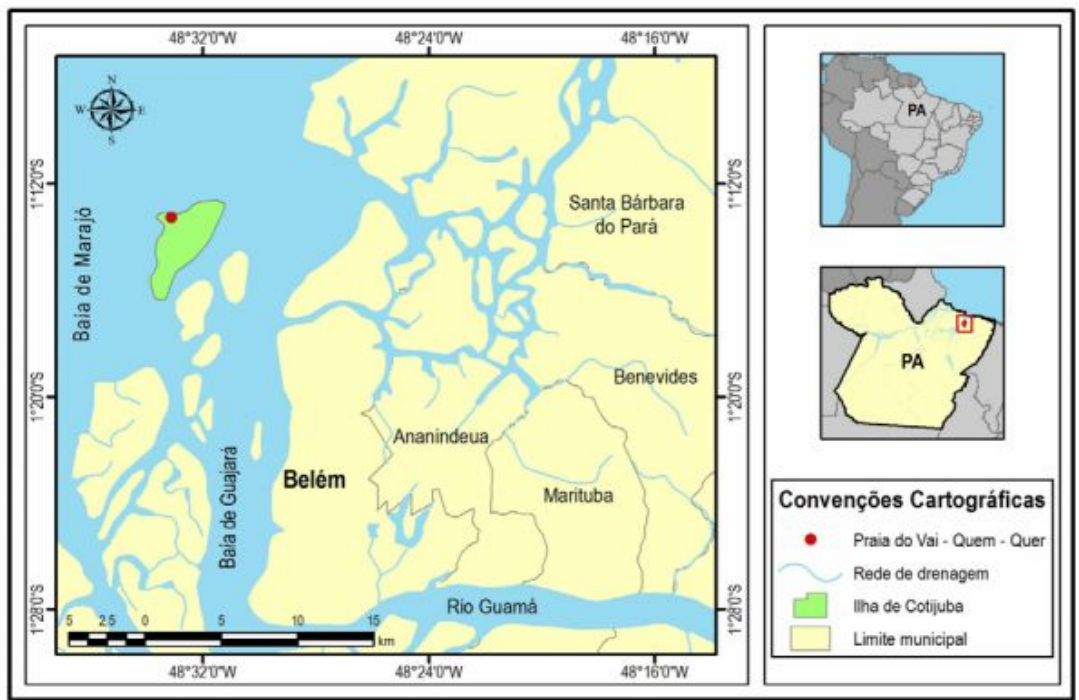

FIGURA 1 - Mapa de localização geográfica da ilha de Cotijuba, Belém, Pará (Fonte: IBGE, 2002) 
Por meio da Lei Municipal 5.621, de 27/11/1990, a Ilha de Cotijuba, é uma Área de Proteção Ambiental (APA), fato que obriga a manutenção de sua vasta cobertura vegetal e a proibição da circulação de veículos motorizados, exceto os de segurança e saúde (SILVA et al., 2014). Devido esta localidade dispor dessa natureza exuberante problematizou-se como objeto de estudo as palmeiras dentro do processo educacional na E.E.E.F.M.P.M.C. (Fig. 2A) em parceria com a Escola Bosque Eidorfe Moreira (E.B.E.M), com sede na llha de Caratateua (Outeiro, PA) e uma das Unidades Pedagógicas na comunidade Faveira, Ilha de Cotijuba (Fig. 2B). Ressalta-se que a E.B.E.M. já possui projetos (p. ex. o AMA - Agentes e Monitores Ambientais) que têm como princípio os eixos temáticos (homem, natureza, sociedade, trabalho e cultura), sendo as palmeiras regionais, um dos focos na inserção do processo educacional como forma de incentivar o desenvolvimento sustentável nesta região.

Buscando esse mesmo intuito, focou-se nos estudos e aplicações, na antiga Escola XV de Agosto, atualmente conhecida como E.E.E.F.M.P.M.C., por ser a mais importante escola de formação existente na Ilha, junto a E.B.E.M., a qual atende crianças, jovens e adultos em suas formações (ensino infantil, fundamental e médio), dando possibilidade para o exercício da cidadania de forma consciente para seus alunos, propondo mudanças políticas, sociais, culturais e espaciais (MELO, 2010). Pareando, assim a práxis educativa em ambas as escolas, possibilitando hábitos e atitudes à formação cidadã com ênfase na Educação Ambiental, que vão desde o manejo com plantas e sementes, até a compostagem, etc.
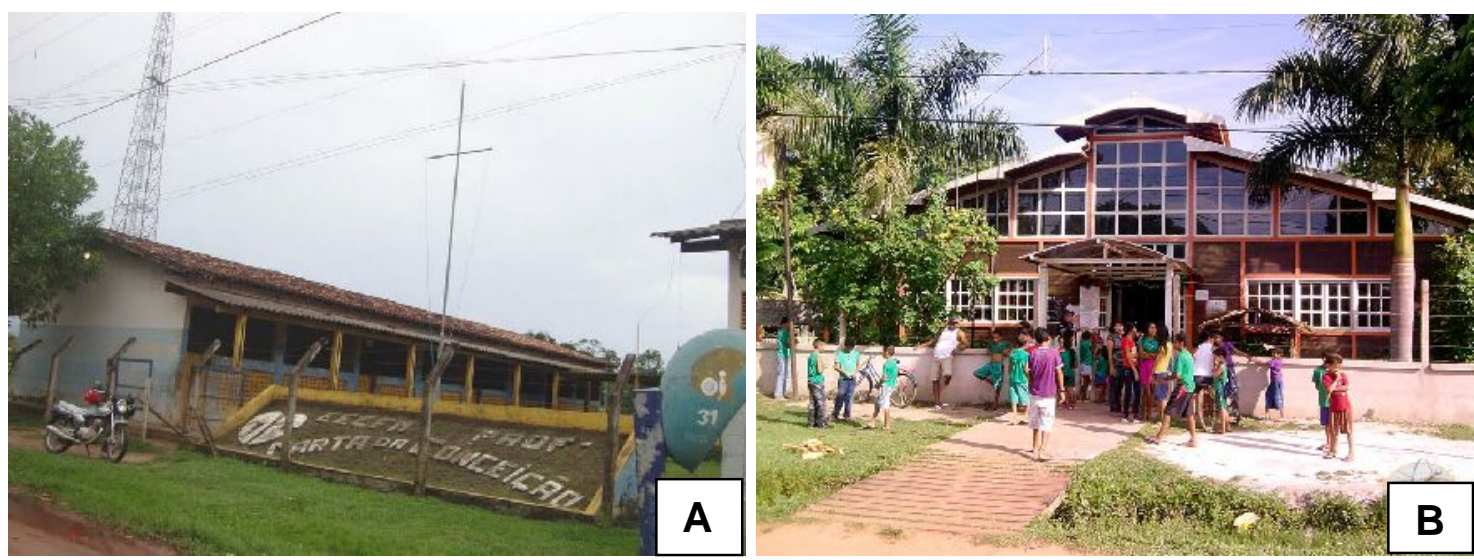

FIGURA 2 - A. Escola Estadual de Ensino Fundamental e Médio Professora Marta da Conceição; B. Fundação Centro de Referência em Educação Ambiental Escola Bosque Prof. Eidorfe Moreira, Unidade Pedagógica Faveira, localizadas na llha de Cotijuba, Belém, PA.

\section{Procedimentos Metodológicos}

Como pressuposto teórico de alicerce a esta pesquisa foi utilizado o livro "Frutíferas e Plantas Úteis na Vida Amazônica" (SHANLEY, 2005), o qual contém conhecimentos tradicionais associados ao conhecimento científico da biodiversidade amazônica, transmitindo de forma fácil e acessível informações sobre botânica, ecologia, usos e manejo de produtos florestais não madeiráveis (PFNMs), de algumas espécies de plantas mais importantes da região, permitindo-se assim a junção entre a educação ambiental e o ensino de ciência, promovendo o uso sustentável dessas plantas que são alguns dos tesouros da nossa floresta, baseado em pesquisas e estudos rigorosos.

Para realização desta pesquisa foi utilizada a metodologia de pesquisa ação e análise qualitativa na modalidade narrativa (CONNELLY; CLANDININ, 1995). Assim, 
foram realizadas visitas, entrevistas gravadas e aplicações dos questionários no período de agosto à novembro de 2018, com método de amostragem acidental (ALBUQUERQUE et al., 2008), junto a comunidade escolar da E.E.E.F.M.P.M.C. As entrevistas foram dirigidas aos alunos, professores, coordenadores e pais de forma inteiramente livre e acidental. Todos os entrevistados concordaram em participar da pesquisa após terem sido informados do seu objetivo, além disso, o mesmo foi previamente autorizado pela Secretaria de Educação do Estado do Pará - SEDUC (PARÁ, 2018)

Durante as entrevistas foram empregados formulários semi-estruturados com 20 itens divididos em duas partes: uma parte introdutória sobre dados pessoais do informante e características socioeconômicas (gênero, idade, estado federativo de nascimento, tempo de instalação na área e atividades econômicas) e outra parte sobre diferentes aspectos do conhecimento e uso de palmeiras na área estudada, a qual deu-se ênfase neste estudo.

Para a culminância, foram desenvolvidas palestras e oficinas participativas através de cartazes, teatros, cantos, vídeos, tecelagem e discussões sobre as palmeiras com os alunos, professores, pais e agentes comunitários. Enfatizando a comunidade sobre o laboratório natural que eles possuem explicando sobre o poder que a "mata" possui através da diversidade de produtos que podem ser usados no extrativismo, como processo cultural e educacional local, bem como o seu resgate de forma continua e participativa, garantindo dessa forma o repasse para as futuras gerações.

\section{RESULTADOS E DISCUSSÕES}

No total, foram realizadas 18 entrevistas e aplicados 100 questionários, o que envolveu 100 pessoas.

\section{Aspecto socioeconômico dos informantes}

O conjunto de informantes incluiu 40 alunos, 20 professores, 20 pais de alunos e 20 lideranças comunitárias, as variáveis encontradas em relação ao sexo foram de 79,03\% (masculino) e 20,96\% (feminino). A faixa etária variou entre 17 e 79 anos, predominando a faixa entre 26 e 55 anos. A naturalidade reportada pelos entrevistados tem origens diversas: $45 \%$ são do próprio estado; $44 \%$ da região nordeste brasileiro, Maranhão, e $11 \%$ de outras partes do país. Um total de $75 \%$ dos entrevistados tem entre seis e 25 anos de residência na área de estudo; 16\% entre um e cinco anos; e 9\% entre 26 e 55 anos na ilha.

Em relação ao sistema produtivo familiar, a maioria das pessoas tem a pesca como única atividade produtiva (66\%), mas também existem aquelas que combinam pesca e agricultura (25\%) e outras que praticam somente a agricultura (9\%). Embora nenhum dos 100 entrevistados tenha citado como atividade produtiva, o extrativismo vegetal, percebeu-se que esta atividade de coleta de produtos naturais, esta frequentemente ocorrendo na localidade, destinada a subsistência familiar, e sendo comercializada esporadicamente, baseada no uso intensivo da mão de obra familiar, com pouca tecnologia e de baixo impacto ambiental.

A palmeira Euterpe oleracea Mart., por exemplo, é um recurso de elevada importância para a comunidade, pois possui uma grande versatilidade de uso já documentada em trabalhos etnobotânicos como o de Canto (2001), Almeida (2010) e Nascimento (2011). Nogueira e Homma (1998) ressaltam que a valorização do fruto teve efeito positivo sobre a conservação de açaizais, onde os açaizeiros, nas áreas próximas aos grandes mercados consumidores de açaí da Amazônia, 
deixaram de ser derrubados para a extração de palmito e passaram a ser mantidos na área para produção de frutos.

\section{Diversidade do uso de palmeiras}

De acordo com os informantes, foram listadas 27 espécies de palmeiras, distribuídas em 15 gêneros. As espécies mais representativas foram $E$. oleracea, com 61,34\%, seguida por Oenocarpus bataua Mart., com 19,70\% e Mauritia flexuosa L., com 9,29\% (Fig. 3). Dentre estas, é importante destacar que Astrocarym vulgare Mart. (62), Mauritia flexuosa (28), E. oleracea (21), Attalea maripa (Aubl.) Mart. (28) e Socratea exorrhiza (Mart.) H.Wendl. (18) apresentaram-se como a mais importante, com respectivas citações.

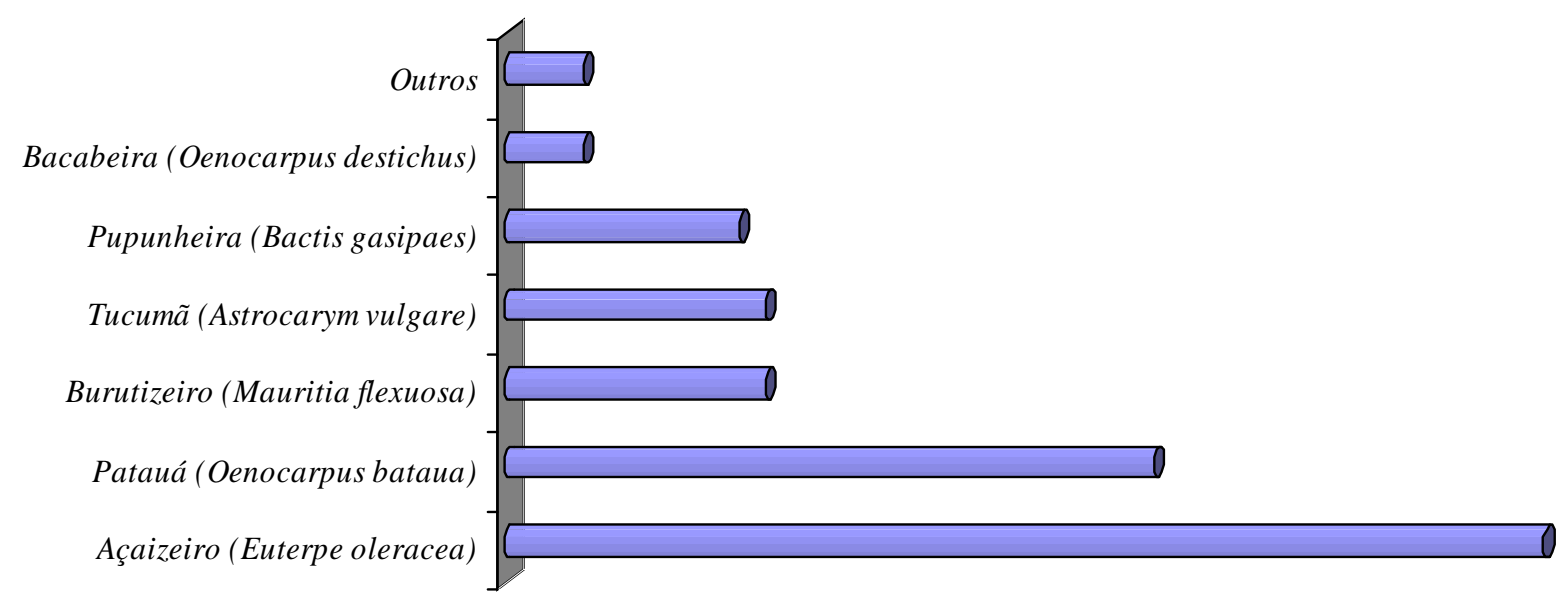

FIGURA 3 - Espécies mais representativas citadas pelos informantes na llha de Cotijuba, Pará

Além disso, estas espécies apresentam expressiva importância cultural e econômica na comunidade, sendo utilizadas para diferentes finalidades, dentre estas, se destaca o uso alimentício (12 spp.), artesanal (9 spp.), construção/doméstica (4 spp.), cosmético (3 spp.) e medicinal (8 spp.). Sendo a categoria alimentícia, artesanal e medicinal e as mais relevantes, por prover recursos para a subsistência e contribuindo para a renda de muitas famílias de extrativistas locais.

Logo, percebe-se que as palmeiras representam um recurso de grande importância para populações locais e muitas vezes essa importância esta relacionada com a multiplicidade de usos que esse grupo possui (BALICK, 1984), tais como construção, alimentação, artesanato, uso ritual e terapêutico (MARTINS et al., 2014), entre outros usos. O tucumanzeiro ou tucumã do Pará ( $A$. vulgare), por exemplo, é um recurso de elevada importância para comunidades locais onde a espécie ocorre, pois possui uma grande versatilidade de usos já documentados em trabalhos etnobotânicos como o de Rocha e Silva (2005) e o de Lima et al. (2013) que registraram 10 e 20 usos para essa espécie, respectivamente.

\section{Resgate e repasse da cultura amazônica na escola}

A importância socioeconômica de Arecaceae está explícita em diversos estudos, uma vez que as espécies úteis dessa família são muitas (BYG; BALSLEV, 2001; ZAMBRANA et al., 2007; MACíA et al., 2011). Fatores socioeconômicos como gênero, idade e escolaridade, além de características culturais, políticas e ecológicas têm sido evidenciadas como variáveis que podem influenciar a 
distribuição de conhecimento dentro de uma comunidade (BYG; BALSLEV, 2004; BALSLEV et al., 2010; SOUTO; TICKTIN, 2012).

Dessa forma, entender a influência dos recursos oferecidos pelas espécies de palmeiras é de suma importância para a manutenção de aspectos sociais e culturais ligados a essa atividade e como inseri-las no processo ensino-aprendizagem. Para isso, os encontros dialogais seguidos da aplicação dos questionários foram fatores primordiais para posteriores reflexões neste processo. Os diálogos foram iniciados, com a explanação do projeto "Arecaceae do dia a dia" para a comunidade, onde após a apresentação, foram solicitados aos moradores que expressarem a importância das palmeiras no dia a dia e o que achavam da inserção desses conhecimentos em sala de aula.

Assim, foram registrados e selecionados os seguintes relatos:

"É muito importante para nós... elas nos dão matérias primas e fonte de alimentação para todos nós que moramos aqui e os professores dos meus filhos utilizando como forma de ensinar né?! Vai ser muito bom para mim e para eles, vamos ter o resgate de uma cultura que herdamos dos nossos bisavós "(PAI DE UM ALUNO).

“(..) Eu acho muito importante conhecermos essa grande riqueza que possuímos né?!... Tem muitas utilidades, até mesmo quando nossos filhos estão doentes obtemos a raiz e a semente de algumas palmeiras como remédios... E essas palmeiras incluídas no ensino-aprendizagem dessas crianças, vai ser muito importante para o conhecimento delas, e nós vamos ter um material riquíssimo para ensinar varias disciplinas tais como a biologia, matemática, historia nutrição, educação ambiental e a própria cultura da comunidade" (PROFESSORA).

“(...) Aqui na comunidade existe um grupo de mulheres que trabalham na confecção de bijuterias com sementes da região e isso ajuda bastante na nossa renda, para isso andamos várzeas, matas e com uma mágica transformamos essas sementes em biojóias. Buscar sementes faz parte do nosso trabalho do ano inteiro" (DONA DE CASA).

“(...) Usamos alguns 'remédios da mata'. As 'palmeiras que curam', as rezas e orações quando vamos partejar, aprendemos com nossa avó, mãe, sogra, tia muitas vezes por necessidades. Fiz o primeiro parto quando tinha 10 anos, aí decidir que queria ser parteira" (PARTEIRA DA LOCALIDADE).

A partir desses relatos, percebe-se que o uso de palmeiras é uma atividade extrativista arraigada na vida dessas pessoas, e que esses saberes podem ser repassados em sala de aula, além de ser recurso poderoso para o ensino de Botânica. Onde os professores de Ciências e Biologia podem conciliar o conhecimento popular dos alunos adquiridos através da convivência familiar ao conhecimento escolar, valorizando a cultura dos educandos e possibilitando assim, que eles adquiram informações a respeito das palmeiras como os mais variados usos, nome científico, morfologia e ecologia. Construindo assim, uma ponte entre o conhecimento escolar e o mundo cotidiano dos alunos. Além, de poderem simular situações em que os alunos devem propor formas de manejo, beneficiamento, uso e comercialização das espécies.

Por exemplo, os professores de Matemática e Física podem elaborar problemas sobre a altura das palmeiras, produção e densidade; os de Química os princípios ativos de folhas, casca, seiva e raízes, além de outras disciplinas que esquecem que o ensino de Botânica pode ser associado à Geografia, História e 
Sociologia que podem associar seus conteúdosà climatologia, à agricultura, aos alimentos, aos remédios etc., o que estaria de acordo com a atual proposta de reformulação da BNCC do ensino Fundamental e Médio, a qual se realça a importância da interdisciplinaridade (SALATINO; BUCKERIDGE, 2016). Segundo Candido (2010, p. 114), "a vida e cultura rural tem uma grande riqueza de valores que pode ser de muita valia para a educação e a escola".

Dessa forma, os professores aprovaram (Fig. 4) a positivação da inserção das palmeiras como uma das maneiras estimuladora para o ensino-aprendizagem. Segundo os relatos dos professores, esse processo buscaestimular o regaste utilitário, simbólico e cultural da comunidade, contribuindo para o conhecimento botânico das espécies, como as características ecológicas, taxonômicas, locais de ocorrências, bem como aspectos relacionados ao manejo e à distribuição das espécies para a região.

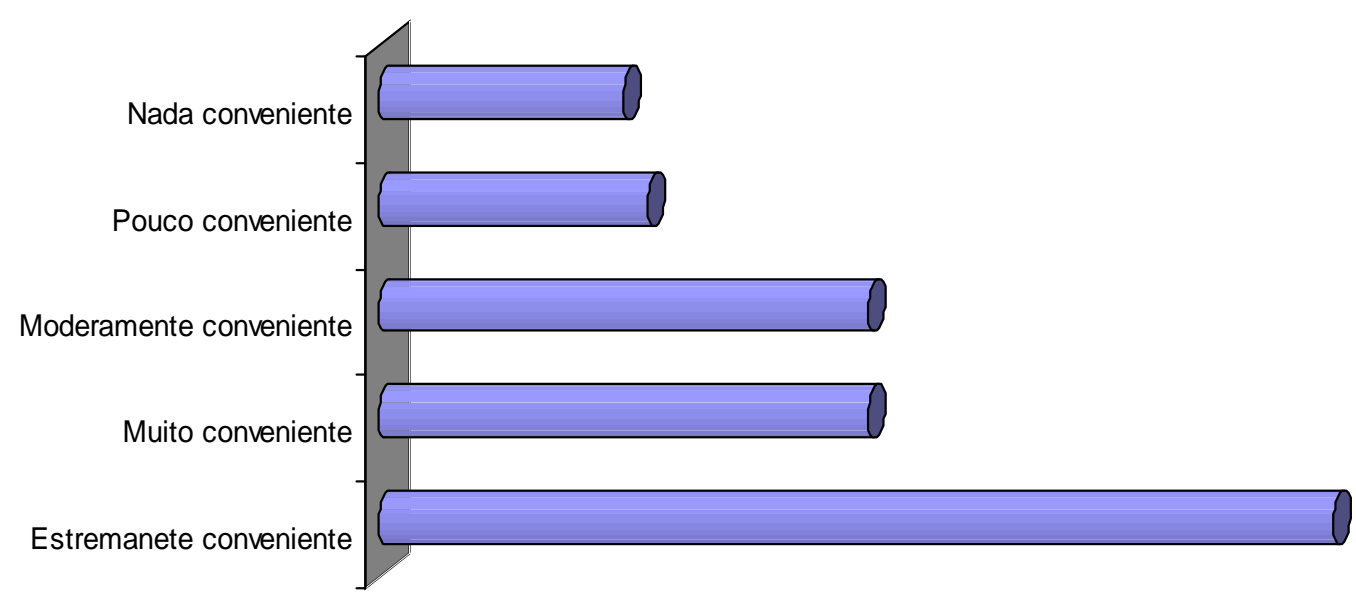

FIGURA 4 - Positivação dos professores, na inserção das palmeiras para o processo de ensinoaprendizagem

Como pode-se observar, as palmeiras têm um grande significado para os envolvidos nesta pesquisa, por contribuir significativamente para o sustento e autonomia dessa comunidade. Por isso, Shanley (2005) considera as palmeiras como entidades educadoras, onde elas educam e cumprem a função de pedagogas, podendo conduzir as pessoas de volta a natureza, tornando-as mais humanizadas. Isto se dar, porque representantes da família Arecaeae, permitem, através da coleta de seus frutos e folhas, a elaboração de diversos produtos tais como artesanato, alimento, medicamentos, materiais de construção etc. (BALICK, 1984).

É notório que quando se consegue obter uma relação entre o cotidiano do aluno e o conteúdo programático escolar é possível ampliar o aprendizado, ou seja, fazer um engajamento do aluno dentro do processo ensino-aprendizagem e tornar o conteúdo potencialmente significativo. Assim, tem-se uma articulação entre a vida e as hipóteses do estudante (DAROS, 2018). Daí a importância de investir, fomentar e criar possibilidades de crescimento e desenvolvimento destas atividades na região local, despertando, ensinado e ativando no individuo um novo conceito de 
participação e responsabilidade social com o meio ambiente, aguçando assim a maneira de vê a botânica de modo diferente.

Como educadores, esta estratégia aprovada pelos professores, usando as palmeiras, é uma de muitas dinâmicas que pode atrair nossos alunos, refutando o que se denominou "cegueira botânica" (WANDERSEE; SCHUSSLER, 2001). Salatino e Buckeridge (2016) ressaltam que a cegueira botânica, deve ser revertida, que metas de curto, médio e longo prazos, podem mudar a imagem que prevalece na mente de grande parte das comunidades discente e docente, e como umas dessas metas é o repasse do valor cultural e econômico das plantas.

Assim, foi reformulada essa meta e abraçada essa proposta, onde muitos moradores ressaltaram abaixo, o valor dado às plantas e que ainda é refletido e absorvido nas lendas e mitos, sobre a origem de diversas espécies nativas. Salatino e Buckeridge (2016) ainda reforçam que temas como esses, são recursos paradidáticos e que despertam a simpatia e o interesse de crianças e jovens por plantas em geral, demonstrando aspectos da cultura e modo de interpretar a natureza das populações pré-colombianas e indígenas. Como enfatiza o morador, a seguir:

\begin{abstract}
"Há muito tempo, quando ainda não existia a comunidade na llha de Cotijuba, vivia no local uma tribo indígena. Nessa época os alimentos eram escassos e por este motivo o cacique tomou uma decisão muito cruel: resolveu que todas as crianças que nascessem a partir daquela data, seriam necessariamente sacrificadas, uma vez que não haveria alimento suficiente para todos. Porém, laça, filha do Cacique, deu a luz a um lindo menino o qual não foi poupado da cruel decisão de seu avô... A índia chorava todas as noites com saudades de seu filho, até que numa noite de lua cheia, a índia ouviu o choro de uma criança. O choro vinha da direção de uma bela palmeira. Quando a índia chegou ao local, seu filho a esperava de braços abertos. Radiante de alegria, laça correu para abraçá-lo, mas quando o fez, a criança misteriosamente desapareceu. No dia seguinte, a índia foi encontrada morta, abraçada ao tronco da palmeira. Seu rosto trazia um suave sorriso de felicidade e seus olhos negros, ainda abertos, fitavam o alto da palmeira que estava carregada de frutinhos escuros. Então, o Cacique mandou que apanhassem os frutinhos e percebeu que deles poderia se extrair um suco quando amassados, que passou a ser a principal fonte de alimento daquela tribo. Este achado fez com que o Cacique suspendesse os sacrifícios e as crianças voltaram a nascer livremente, pois a alimentação já não era mais problema na tribo. Em agradecimento ao deus Tupã e em homenagem a sua filha, o Cacique deu o nome de AÇAí aos frutinhos encontrados na palmeira, que é justamente o nome de IAÇA invertido" (MORADOR DA LOCALIDADE).
\end{abstract}

Diz ainda, um morador de 84 anos de idade, que a lenda do buriti é muito antiga, em relação as demais conhecidas na Amazônia, desde de quando menino, seus avôs já contavam essa lenda no interior dos municípios de Cametá e Limoeiro de Ajurú - PA, como enfatiza a seguir:

"que em uma aldeia dos índios Tucujus, o cacique era pai de uma linda índia,
a mais bonita da tribo, ela adorava ir à beira do rio para apreciar a correnteza.
Certo dia um boto viu a linda índia e se apaixonou. O boto em forma de um
homem todo de branco, todos os dias ia ao encontro da linda índia, até que
um dia ela se apaixonou por ele e ficou gestante, em seguida o boto sumiu.
Seu pai queria matá-lo, pois, queria saber quem era o pai, ela respondeu que
era de um homem que se vestia de branco e que tinha sumido. A criança
nasceu, mas ao completa cinco anos faleceu, sem saber a causa. A índia 
chorou muito, enterrou a criança á beira de um lago e todos os dias iam visitá-la. Em cima da sepultura nasceu uma linda e viçosa palmeira, a índia ficou tão maravilhada que achou que era sua filha. Com o passar do tempo à árvore ficou tão grande e deu lindos frutos escamosos. A índia resolveu dar nome a árvore que se chamou de buritizeiro. Daí a origem dos grandes buritizais nos rios, lagos e igarapés, que alimentam povos indígenas e ribeirinhos.

Essas histórias e lendas contadas pelos moradores da comunidade na escuridão da noite são assustadoras que deixam as pessoas com medo. Mas, percebe-se que em diversas dessas lendas, aspectos da morfologia e outras características das plantas são realçadas e muitas vezes implícitas, contribuindo assim, para o conhecimento não só de plantas úteis, mas também de algumas de suas características morfológicas e até mesmo fisiológicas, que podem ser discutidas e apresentadas em sala de aula, minimizando, assim os efeitos do distanciamento das pessoas em relação às plantas.

Com base no que foi observado é possível organizar competências metodológicas multidisciplinares para melhor aproveitar elementos encontrados ao redor do ambiente escolar. O foco deste estudo foi nos representantes de Arecaceae, mas ressalta-se que a mesma abordagem pode ser efetuada com outros representantes da flora em qualquer ambiente. É muito importante que para este tipo de ensino-aprendizagem o professor tenha um bom conhecimento sobre o tema abordado. Ao associar o conhecimento do professor com a vivência do aluno, novos caminhos serão construídos com uma aprendizagem consolidada e aplicável em sua realidade.

\section{CONCLUSÕES}

Diante disso, pode-se observar através deste estudo que, apesar das dificuldades encontradas no ensino de Botânica serem diversas, é possível inovar o ensino e aproximar os discentes do conteúdo através de metodologias e ferramentas de seu cotidiano, como é o caso das palmeiras. A inserção das palmeiras, como recurso metodológico para uma aprendizagem significativa é de grande valia, por ser um elemento sócio-cultural presente na vida dessa comunidade e que pode superar as limitações impostas pela cegueira botânica, fazendo com que, o discente seja capaz de observar, construir e reconstruir conceitos acerca das principais características morfológicas, utilização e importância das plantas, promovendo uma aprendizagem lógica e efetiva dos conteúdos Botânicos.

Portanto, repensar a forma de ensino e a condução das aulas, para atrair a curiosidade dos discentes, deve ser um dos principais objetivos dos professores, pois é dever do mesmo, explanar os conteúdos aos discentes de modo que estes sejam capazes de construir conceitos. O presente estudo mostra a importância de dinamizar o ensino através de metodologias alternativas do dia a dia dos discentes, e que a escola pode tornar-se um instrumento de ensino e pesquisa, utilizando as famílias como meio de descoberta para estas estratégias diferenciadas de ensinoaprendizagem de botânica. Logo, os alunos tornam-se amantes da natureza e multiplicadores de conhecimentos nesta área, contribuindo e provendo laboratórios naturais com fins educativos e com interesse para desenvolver pesquisa básica e aplicada em todas as áreas da ciência. Desta forma, trabalhar conservação e respeito a natureza se torna consequência de ações oriundas da base educacional de todo cidadão. 


\section{REFERÊNCIAS}

ALBÁN, J.; MILLÁN, B.; KHAN, F. Current status of ethnobotany research on palms from Peru. Revista Peruana de Biologia n.15, p. 133-142, 2008.

ALBUQUERQUE, U. P.; LUCENA, R. F. P.; ALENCAR, N. L. Métodos e técnicas para coleta de dados etnobotânicos. 2ª Edição. Recife: Livro rápido/ NUPEEA, 2008. $323 \mathrm{p}$.

ALMEIDA, A. F. Análise etnoecológica da floresta de várzea da ilha de Sororoca, Ananindeua, Pará, Brasil. 2010. 61 f. Dissertação (Mestrado em Ciências Ambientais) - Instituto de Geociências, Universidade Federal do Pará, Museu Paraense Emílio Goeldi e EMBRAPA, Belém, 2010.

ANDERSON, A. B.; MAY, P. H.; BALICK, M. J. The subsidy from nature: Palm forests, peasantry, and development on an Amazon frontier. New York: Columbia University Press, 1991. 233 p.

AUSUBEL, D. P. A. A aprendizagem significativa: a teoria de David Ausubel. São Paulo: Moraes, 1982. $112 \mathrm{p}$.

BALICK, M. J. Ethnobotany of palms in the Neotropics. Advances in Economic Botany n. 1, p. 9-23, 1984.

BALICK, M. J.; KNUDSEN, T. R.; BYG, A.; KRONBORG, M.; GRANDEZ, C. Traditional knowledge, use, and management of Aphandra natalia (Arecaceae) in Amazonian Peru. Economic Botany n. 64, p. 55-67, 2010.

BATES, D.M. Utilization pools: a framework for comparing and evaluating the economic importance of palms. Advances in Economic Botany n. 6, p. 56-64, 1988.

BERKES, F.; KISLALIOGLU, M.; FOLKE, C.; GADGIL, M. Exploring the basic ecological unit: ecosystem-like concepts in traditional societies. Ecosystems n. 1, p. 409-415, 1998.

BFG - Brazilian Flora 2020: Innovation and collaboration to meet Target 1 of the Global Strategy for Plant Conservation (GSPC). Rodriguésia v. 69, n. 4, p. 15131527, 2018.

BONDAR, G. Palmeiras do Brasil. Instituto de Botânica de São Paulo, São Paulo, 1964. $159 \mathrm{p}$.

BORCHSENIUS, F.; BORGTOFT, H.; BALSLEV, H. Manual to the palms of Ecuador. Reports - Association of American Universities n. 37, p. 1-217, 1998.

BRASIL. Lei no 9.394, de 20 de dezembro de 1996. Estabelece as diretrizes e bases da educação nacional. Diário Oficial da União, Brasília, 23 de dezembro de 1996. Disponível em: http://www.planalto.gov.br/ccivil_03/leis/L9394.htm. Acesso em: 23 mar. 2018. 
BRASIL. Ministério da Educação; Secretaria de Educação Básica; Secretaria de Educação Continuada, Alfabetização, Diversidade e Inclusão; Secretaria de Educação Profissional e Tecnológica. Conselho Nacional de Educação; Câmara de Educação Básica. Diretrizes Nacionais da Educação Básica. Brasília: MEC; SEB; DICEI, 2013. Disponível em: http://portal.mec.gov.br/index.php?option=com_docman\&view=download\&alias $=1344$ 8-diretrizes-curiculares-nacionais-2013-pdf\&ltemid=30192. Acesso em: 16 out. 2018.

BRASIL. Base Nacional Comum Curricular (BNCC). http://basenacionalcomum.mec.gov.br/. Acesso em: 02 jan. 2019.

BYG, A.; BALSLEV, $H$. Diversity and use of palms in Zahamena, eastern Madagascar. Biodiversity and Conservation n. 10, p. 951- 970, 2001.

BYG, A.; BALSLEV, H. Factors affecting local knowledge of palms in Nangaritza Valley in South-Eastern Ecuador. Journal of Etnhnobiology v. 24, n. 2, p. 255-278, 2004.

BYG, A.; BALSLEV, H. Palms in Indigenous and Settler Communities in Southeastern Ecuador: Farmers "perceptions and cultivation practices". Agroforesty Systems n. 67, p. 147-158, 2006.

CAMPOS, M.T.; EHRINGHAUS, C. Plant virtues are in the eyes of the beholders: a comparison of known palm uses among indigenous and folk communities of southwestern Amazonia. Economic Botany n. 57, p. 324-344, 2003.

CANDIDO, A. Os parceiros do Rio Bonito. Rio de Janeiro: Duas Cidades, 2010. $336 \mathrm{p}$.

CONNELLY, F.M.; CLANDININ, D.J. Relatos de experiencia e investigación narrativa. In: LARROSA, Jorge et al. Déjame que te cuente: ensayos sobre narrativa y educación. Barcelona: Editorial Laertes. 1995. p.15-59.

CANTO, S. A. E. Processo Extrativista do Açaí: Contribuição da Ergonomia com Base na Análise Postural Durante a Coleta dos Frutos. 2001. 114 f. Dissertação (Mestrado em Engenharia de Produção) - Engenharia de Produção, Universidade Federal de Santa Catarina, Florianópolis, 2001.

DAROS, T. Por que inovar na educação? In: CAMARGO, F. \& DAROS, T. A sala de aula inovadora: estratégias pedagógicas para fomentar 0 aprendizado significativo. Porto Alegre: Penso Editora LTDA. 2018. 03-07 p.

DRANSFIELD, J.; UHL, N. W.; ASMUSSEN, C. B.; BAKER, W. J.; HALEY, M. M.; LEWIS, C. E. Genera Palmarum: The Evolution and Classification of Palms. Kew Publishing, Royal Botanical Gardens, Kew. 2008. 744 p.

FREIRE, P. Pedagogia do oprimido. Rio de Janeiro: Paz e Terra, 1987. 256 p.

FREIRE, P.; SHOR, I. Medo e ousadia: o cotidiano do professor. 12. ed. Rio de Janeiro: Paz e Terra, 2008. 224 p. 
HENDERSON, A.; GALEANO, G.; BERNAL, R. Field guide to the palms of the Americas. Princeton University Press, Princepton, New Jersey, 1995. 352 p.

IBGE. (Instituto Brasileiro de Geografia e Estatística). Disponível em: http://www.ibge.gov.br/home/. Acesso em: 8 de set. de 2018.

LIMA, L. P.; GUERRA, G. A. D.; MING, L. C.; MACEDO, M. R. A. Ocorrências e usos do tucumã (Astrocaryum vulgare Mart.) em comunidades ribeirinhas, quilombolas e de agricultores tradicionais no município de Irituia, Pará. Amazônica - Revista de Antropologia v. 5, n. 3, p. 762-778, 2013.

LORENZI, H. Palmeiras do Brasil: exóticas e nativas. Nova Odessa: Editora Plantarum, 1996. 303 p.

MACHADO, F. S. Manejo de Produtos Florestais Não Madeireiros: um manual com sugestões para o manejo participativo em comunidades da Amazônia. Rio Branco, Acre: PESACRE e CIFOR, 2008.

MACÍA, M. J., ARMESILLA, P. J., CÁMARA-LERET, R., PANIAGUA-ZAMBRANA, N., VILLALBA, S., BALSLEV, H.; PARDO-DE-SANTAYANA, M. Palm uses in northwestern South America: A quantitative review. The Botanical Review n. 77, p. 462-570, 2011.

MARTINS, R. C.; FILGUEIRAS, T. S.; ALBUQUERQUE, U. P. Use and Diversity of Palm (Arecaceae) Resources in Central Western Brazil. The Scientific World Journal, ID 942043, 14 p., 2014. Disponível em: http://dx.doi.org/10.1155/2014/942043

MAUNDER, M.; LYTE, B.; DRANSFIELD, J.; BAKER, W. The conservation value of botanic garden palm collections. Biological Conservation n. 98, p. 259-271, 2001.

MELO, O. C. O lugar e a comunidade na Ilha de Cotijuba - PA. 2010. $192 f$. Dissertação (Pós-graduação em Geografia) - Instituto de Filosofia e Ciências Humanas, Universidade Federal do Pará, Belém, 2010.

NASCIMENTO, A. R. T. Riqueza e etnobotânica de palmeiras no território indígena krahô, Tocantins, Brasil. Floresta v. 40, n. 1, p. 209-220, 2010.

NASCIMENTO, E. S. do. Levantamento dos conhecimentos etnobotânicos de comunidades ribeirinhas do estuário amapaense. Macapá: UNIFAP, 2011. 86 p.

NOGUEIRA, O. L.; HOMMA, A. K. O. Importância do manejo de recursos extrativos em aumentar o carrying capacity: o caso de açaizeiros (Euterpe oleracea Mart.) no estuário amazônico. Poematropic n. 2, p. 31-35, 1998.

PARÁ. Secretaria de Educação do Estado do Pará - SEDUC. Disponível em: http://www.seduc.pa.gov.br/site/seduc/index. Acesso em: 8 de dez. de 2018. 
ROCHA, A. E. S.; SILVA, M. F. F. Aspectos fitossociológicos, florísticos e etnobotânicos das palmeiras (Arecaceae) de floresta secundária no município de Bragança, PA, Brasil. Acta Botanica Brasilica n. 19, p. 657-667, 2005.

SALATINO, A.; BUCKERIDGE, M. "Mas de que te serve saber botânica?". Estudos Avançados v. 30, n. 87, 177-196, 2016. Disponível em: http://dx.doi.org/10.1590/S0103-40142016.30870011

SÁNCHEZ, C. T. O mundo da vida no estuário amazônico: ecologia política da biodiversidade no arquipélago de Belém do Pará-Brasil. 2005. 361f. Tese (Pósgraduação em Desenvolvimento, Agricultura e Sociedade) - Instituto de Ciências Humanas e Sociais, Universidade Federal Rural do Rio de Janeiro, Rio de Janeiro, 2005.

SANTOS, R. S.; COELHO-FERREIRA, M. Artefatos de miriti (Mauritia flexuosa L.f.) em Abaetetuba, Pará: da produção à comercialização. Boletim Museu Paraense Emílio Goeldi/Ciências Humanas n. 6, p. 559-571, 2011.

SANTOS, R. S.; COELHO-FERREIRA, M. Estudo etnobotânico de Mauritia flexuosa L.f. (Arecaceae) em comunidades ribeirinhas do Município de Abaetetuba, Pará, Brasil. Acta Amazônica n. 42, p. 1-10, 2012.

SHANLEY, P. Frutíferas e Plantas Úteis na Vida Amazônica. Shanley, P., Medina, M.; ilustrado por Silvia Cordeiro, Antônio Valente, Bee Gunn, Miguel Imbiriba, Fábio Strympl. Belém: CIFOR, Imazon, 2005. 300 p.

SILVA, G. V. da; CARIPUNA, L. A.; SILVA, M. L. da; PONTES, N. A.; SILVA, G. S. Percepção ambiental na área de proteção ambiental na llha de Cotijuba, Belém, Pará. Enciclopédia biosfera, Centro Científico Conhecer v.10, n.18; p. 3977-3985, 2014.

SODRÉ, J. B. Morfologia das palmeiras como meio de identificação e uso paisagístico. 2005. 65f. Monografia (Curso de especialização em Plantas Ornamentais e Paisagismo) - Universidade Federal de Lavras, Lavras, Minas Gerais/Brasil, 2005.

SOUTO, T.; TICKTIN, T. Understanding Interrelationships among Predictors (Age, Gender, and Origin) of Local Ecological Knowledge. Economic Botany 66, 149-164, 2012. Disponível em: http://dx.doi.org/10.1007/s12231-012-9194-3

WANDERSEE, J. H.; SCHUSSLER, E. E. Towards a theory of plant blindness. Plant Science Bulletin, v. 47, n. 1, p. 2-9, 2001.

ZAMBRANA, N. Y. P.; BYG, A.; SVENNING, J. C.; MORAES, M.; GRANDEZ, C.; BALSLEV, $H$. Diversity of palm uses in the western Amazon. Biodiversity and Conservation n. 16, p. 2771-2787, 2007. 